\title{
Identification of material properties of foam used in motorcyclist protective equipment based on obtained experimental data and optimization algorithm
}

\author{
S. Kaňákováa ${ }^{a, *}$, R. Kottner ${ }^{b}$ \\ ${ }^{a}$ Faculty of Applied Sciences, University of West Bohemia, Univerzitni 8, 30100 Plzeñ, Czech Republic \\ ${ }^{b}$ NTIS - New Technologies for the Information Society, Faculty of Applied Sciences, University of West Bohemia, Technická 8, 30100 Plzeñ, \\ Czech Republic
}

Received 12 July 2018; accepted 19 December 2018

\begin{abstract}
This article deals with the material parameters identification of foam used in motorcyclist protective equipment, such as a shoulder pad. Experiments, namely a compression, a tension and an impact test were performed to obtain source and target data. The low-density foam material model was selected to characterize the foam. The material model was used in the finite element simulation. The numerical simulation of the impact test was used for an optimization. The parameters of the model were identified using an evolutionary algorithm in the optiSLang 3.0 software. The obtained material model will be used for the simulation of the standard test of protectors consisting of the foam used in motorcyclist protective equipment.
\end{abstract}

(c) 2018 University of West Bohemia. All rights reserved.

Keywords: identification, impact, low-density foam, material model, shoulder pad

\section{Introduction}

With progression of technology and ability to create faster means of transport emerged necessity to create better protective equipment. To save time and finances, which would be required for experimental testing, arose an idea to create a simulation corresponding to the standardized tests, such as in [3]. It would make possible to evaluate certain designs as unsuitable using only numerical models. However, these models would require knowledge of the equipment measurements and, furthermore, ability to describe its material mechanical properties. This article deals with this problem.

The aim of this article was to identify material properties of the foam used in motorcyclists shoulder pads (pads consisting of the foam and layer of leather). Experimental measurements were performed to gain target data, specifically a compression, a tension and an impact test. The numerical simulation of the impact test was created in Python in parametric expression for Abaqus. The low-density foam was selected as a suitable material model. Its parameters were identified in the optiSLang software.

Similar problem was solved in [8], where three cycles of a loading-unloading compression test and three tension tests were performed to maintain target data for the identification of the low-density foam model parameters. The tests were performed only for one strain rate. Foam used in car seats was modelled using LS-DYNA. Interesting part of the cited article is

\footnotetext{
*Corresponding author. Tel.: +420 377632 373, e-mail: kanaksan@students.zcu.cz. https://doi.org/10.24132/acm.2018.467
} 
comparison of the optimized model having three different sizes of elements. It is shown that a mesh consisting of bigger elements is more suitable for the material parameters identification. The identified material parameters did not include strain rate dependence, which is one of the main differences between [8] and presented work. Other difference is using data from the impact test as the identification target.

Obtained material model of the foam will be supplemented by the model of leather [2] and together will be used during the numerical simulation of the protectors standard test ČSN EN 1621-1. Furthermore, these models will be used for motorcyclist crush simulations such as [4].

\section{Low-density foam}

Low-density foam is a material model appropriate for numerical simulations of energy absorbing foams in Abaqus. This material model is suitable for highly compressible foams sensitive to deformation speed [1].

The material model is simply defined by a set of discrete points from dependency curves of the nominal stress on the nominal strain for the uniaxial compression and tension test data for different strain rates. The curves of the nominal stress dependencies are extrapolated from the input values. If it is required, the model allows to enter unloading values, which are specified by negative value of the strain rate [1].

It is necessary to complete this model with a mass density value.

\section{Experiments}

Experimental measurements were performed to acquire data which would make possible to fit the material model: a tension test, a compression test, and an impact test. Experimental samples were cut directly from shoulder protectors. More detailed description of the experiments is in [5] and [9].

\subsection{Compression test}

The compression test was performed on the ZWICK/ROELL Z050 universal testing machine for strain rate $0.001 \mathrm{~s}^{-1}$ and $1 \mathrm{~s}^{-1}$. Samples were compressed until its compressive nominal strain reached value of 0.8 . Then the sample was left to relax for 60 seconds and, subsequently, it was unloaded. The compressive reaction force was measured.

Obtained data of the compressive nominal stress in the dependency on the compressive nominal strain are shown in Fig. 1.

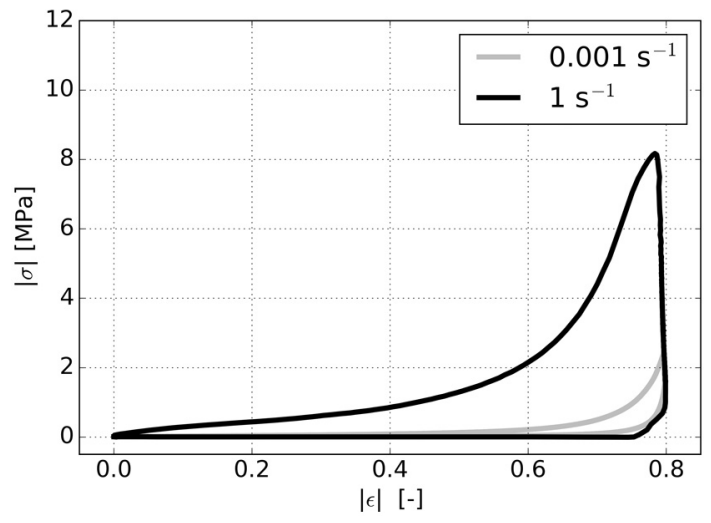

Fig. 1. Obtained data from compression test

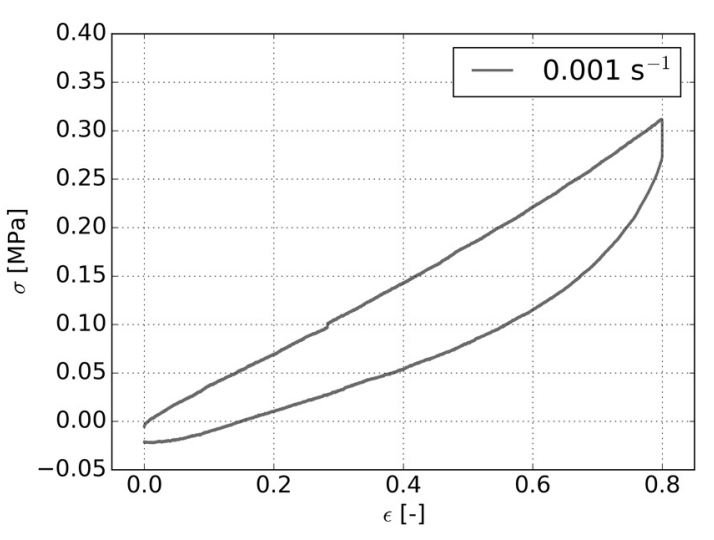

Fig. 2. Obtained data from tension test 


\subsection{Tension test}

The tension test was performed on the ZWICK/ROELL Z050 universal testing machine for the strain rate $0.001 \mathrm{~s}^{-1}$. This experiment was designed to reflect the compression test, therefore, samples were loaded until its nominal strain reached value of 0.8 . Then the sample was left to relax for 60 seconds and, subsequently, it was unloaded. The reaction force was measured.

Obtained data of the nominal stress in the dependency on the nominal strain are displayed in Fig. 2.

\subsection{Impact test}

The impact test was performed on a drop tower created by employees of the University of West Bohemia [6]. An impactor with flat head was used for this experiment. The impactor weight was $2.454 \mathrm{~kg}$. The impactor displacement $h$, which represents a position of the bottom side of the impactor head above a base block, and the force between main impactor mass and the impactor head $F$ were measured [5].

The impact test was realized for three different impact velocities: $1 \mathrm{~ms}^{-1}, 2 \mathrm{~ms}^{-1}$, and $3 \mathrm{~ms}^{-1}$. Results of the impact test are displayed in Figs. 3 and 4.

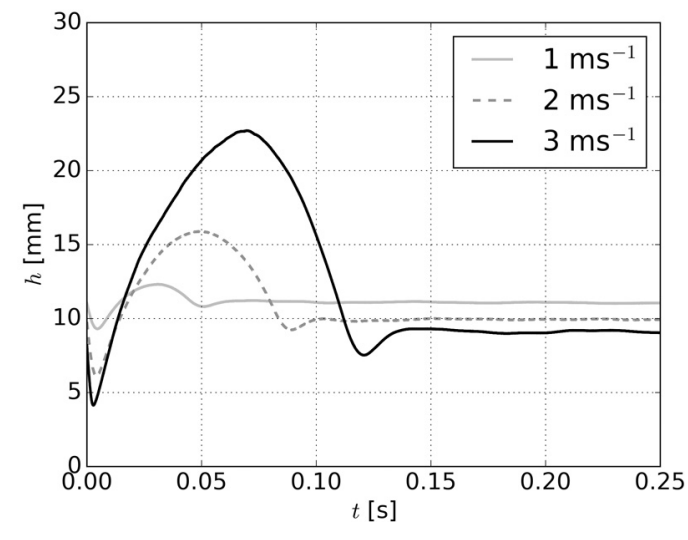

Fig. 3. Impactor displacement

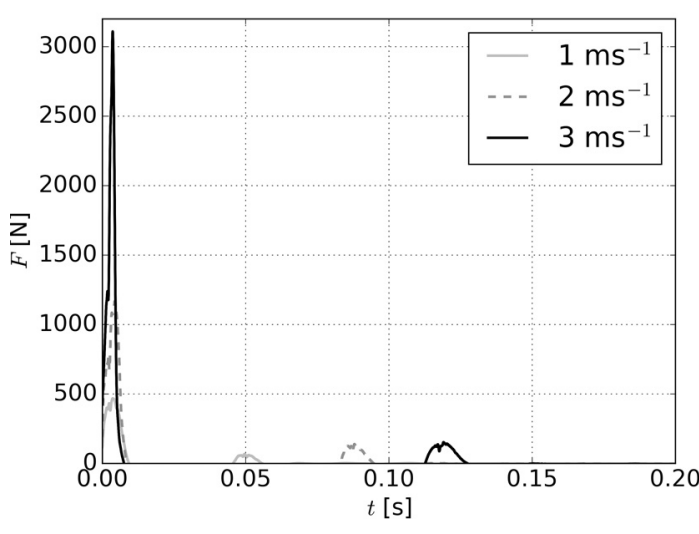

Fig. 4. Force during impact test

\section{Models}

The performed experiments were simulated using the finite-element system Abaqus. Only the impact test was selected for an identification algorithm. The impact test simulation was created in Python in the parametric expression for Abaqus.CAE. The fact that the model used parametric expression in geometry, load, and material properties was crucial for subsequent identification.

\subsection{Impact test model}

The model of a rectangular sample using the Low-density foam material model was created. The bottom side of the sample had restricted displacements in all directions, which should substituted the base block of the drop tower and fastening of the sample by a double-sided adhesive tape.

The model of the impactor had simple rectangular shape (which was not in agreement with the real impactor, see [9]). Its Youngs modulus was $210 \mathrm{GPa}$ and Poisson ratio was 0.3. Its density was calculated to match weight of the real impactor. The impactor model was placed directly on the top of the sample, with an initial velocity condition. The model is shown in Fig. 5. 


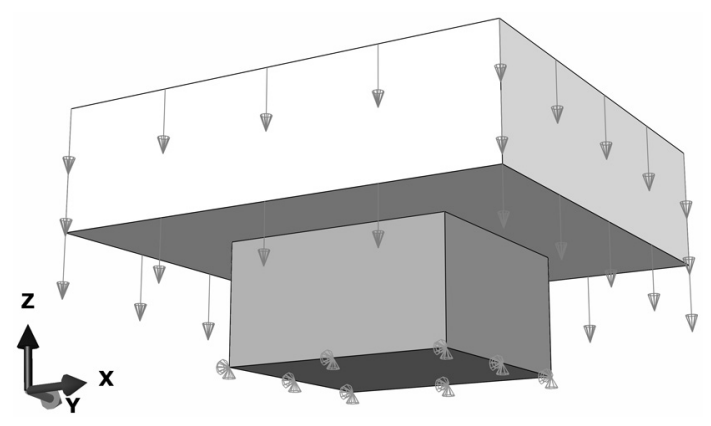

Fig. 5. Model of impact test -1 element

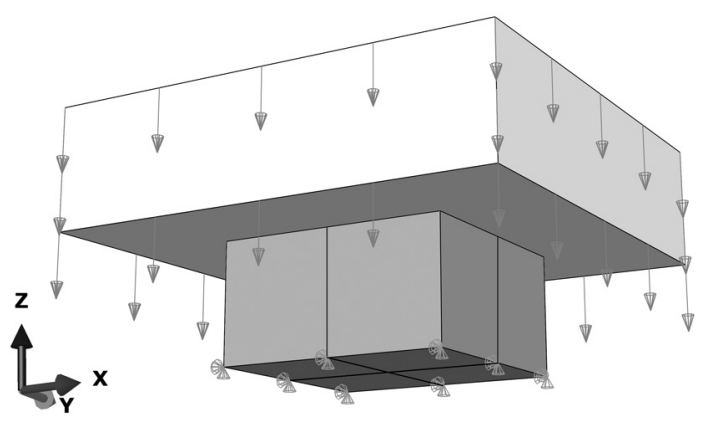

Fig. 6. Model of impact test -4 elements

Mesh for the identification consisted of one element. This mesh was chosen because of its time saving aspect and the stability of the solution. The elements had tendency to collapse during the simulation, but the usage of the one element model reduces the probability of this situation. Final model was also submitted with different mesh shown in Fig. 6. This mesh consisted of four elements and its purpose was to demonstrate an accuracy of the solution obtained from 1 element mesh. Simulated time was $0.2 \mathrm{~s}$, this value was chosen with regard to the impact test, where displacements and forces were not significant after exceeding the time of 0.2 s, see Figs. 3 and 4 .

The dependencies of the reaction force and the impactor displacement on time were the output data.

\subsection{Compression and tension tests models}

The numerical simulations of the compression and tension tests were created to validate the identified material model. The model parameters were identified to characterize loading parts of the performed experiments.

The model of the compression sample was axisymmetric. Its mesh consisted of two elements. Symmetry of the tension sample was used, therefore, only a quarter of the sample was modeled. Mesh of the model consisted of one element.

\section{Identification of material parameters}

The identification was performed in optiSLang 3.0 on the basis of the following target function:

$$
\begin{aligned}
f_{i}= & 5 \cdot \frac{\sqrt{\left(F_{\max }^{\exp }-F_{\max }^{\mathrm{opt}}\right)^{2}}}{F_{\max }^{\exp }}+2 \cdot \frac{\sqrt{\left(h_{\max }^{\exp }-h_{\max }^{\mathrm{opt}}\right)^{2}}}{h_{\max }^{\exp }}+ \\
& 2 \cdot \frac{\sqrt{\left(h_{\min }^{\exp }-h_{\min }^{\mathrm{opt}}\right)^{2}}}{h_{\min }^{\exp }}+1 \cdot \sum_{j=1}^{10} \frac{\sqrt{\left(h^{\exp }(\Delta t \cdot j)-h^{\mathrm{opt}}(\Delta t \cdot j)\right)^{2}}}{h^{\exp }(\Delta t \cdot j)}, \\
\Delta t= & 0.02, \quad i=\{1,2,3\}
\end{aligned}
$$

where $F_{\max }^{\exp }$ is the maximal force from the experiment, $F_{\max }^{\text {opt }}$ is the maximal force from the simulation, $h_{\max }^{\exp }$ is the maximal impactor displacement from the experiment, $h_{\max }^{\mathrm{opt}}$ is the maximal impactor displacement from the simulation, $h_{\min }^{\exp }$ is the minimal impactor displacement from the experiment, $h_{\mathrm{min}}^{\mathrm{opt}}$ is the minimal impactor displacement from the simulation, $\Delta t$ is the time step size, $h^{\exp }(\Delta t \cdot j)$ is the displacement value in required time from the experiment, $h^{\mathrm{opt}}(\Delta t \cdot j)$ is the displacement value at the required simulation time, and $i$ is the impactor velocity value in $\mathrm{ms}^{-1}$. 
The target function expressed the difference between force and displacement responses of the impact test and its simulations. The experiment with the higher impact velocity had higher weight for the identification. The final function was

$$
f=1 \cdot f_{1}+1.5 \cdot f_{2}+2 \cdot f_{3}
$$

Identified parameters of the Low-density foam material model were the nominal stress and nominal strain values of the stress-strain curves for four strain rates: $k=\{91,182,273,403\} \mathrm{s}^{-1}$. These strain rates were calculated as strain rates of compression tests corresponding to the strain rates during the impact test and during the standard test of the protectors CSN EN 1621-1.

Key parameters for the material model were density of $287 \mathrm{~kg} \mathrm{~m}^{-3}$, loading and unloading curves obtained from the tension and the compression tests. The points of the loading compression curves themselves were used for the identification as is shown in Fig. 7, strain rates $0.001 \mathrm{~s}^{-1}$ and $1 \mathrm{~s}^{-1}$. According to [7], it was possible to expect that the identified curves would have similar shape, only mutually displaced. Therefore, for the first part of the identification, only four auxiliary constant values of the nominal stress $C_{91}=610 \mathrm{kPa}, C_{182}=4150 \mathrm{kPa}$, $C_{273}=8250 \mathrm{kPa}$, and $C_{403}=30900 \mathrm{kPa}$ were identified, one constant $C_{k}$ for one of the four strain rates $k$. These constants were created purely for this optimization in order to facilitate the identification process. Each constant was gradually added to the nominal stress points from the nominal stress-nominal strain curve for strain rate of $1 \mathrm{~s}^{-1}$ and so basic image of the input data was created (see Fig. 7). After the maintaining of approximate values for each curve, individual stress and strain values were optimized. Default constant values of the relaxation coefficients $\alpha=2 \mathrm{~s}, \mu_{0}=0.0001 \mathrm{~s}$, and $\mu_{1}=0.005$ were used. These coefficients determine the relation between loading and unloading curves [8].

An evolutionary algorithm was used for the identification with a starting population and the tournament selection, size of the tournament was 5 .

The identified material parameters are shown in Fig. 8. The circles represent the identified values, the squares represent the experimental data.

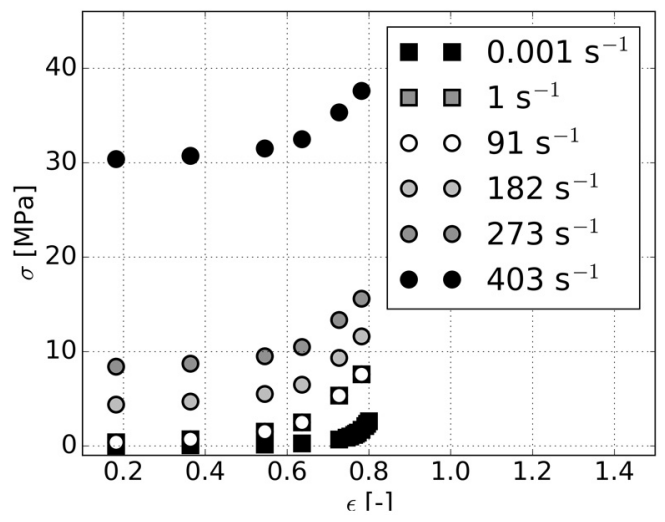

Fig. 7. Approximate values of parameters

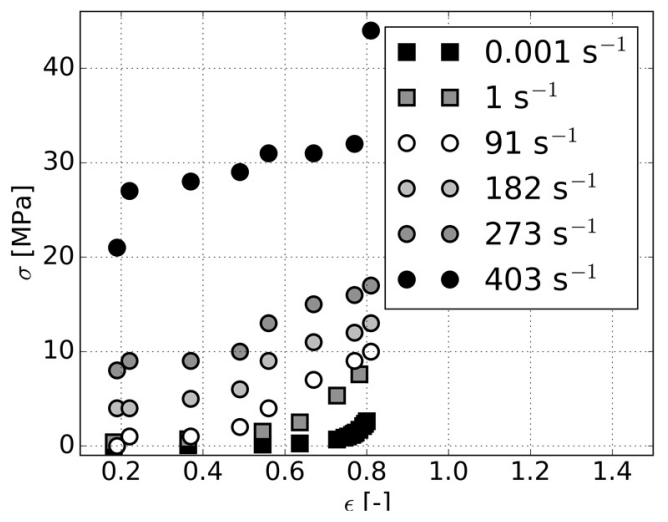

Fig. 8. Identified parameters

\section{Results}

The numerical simulations of the impact test with the identified model are presented in Figs. 9-14 and Table 1. Displacement curves for the impact velocities $2 \mathrm{~ms}^{-1}$ and $3 \mathrm{~ms}^{-1}$ are in good agreement, however, the curve for the impact velocity $1 \mathrm{~ms}^{-1}$ does not have same character. This is probably due to a shortage of stress-strain dependency curves for slower strain rates. 


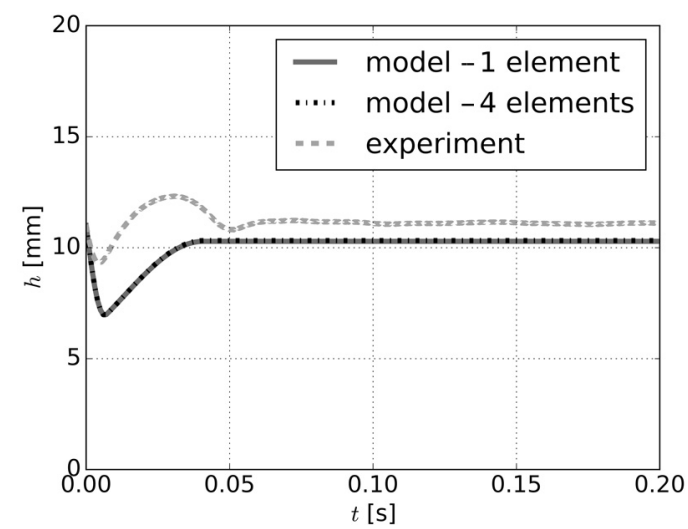

Fig. 9. Comparison of displacement of identified model and impact test for $1 \mathrm{~ms}^{-1}$

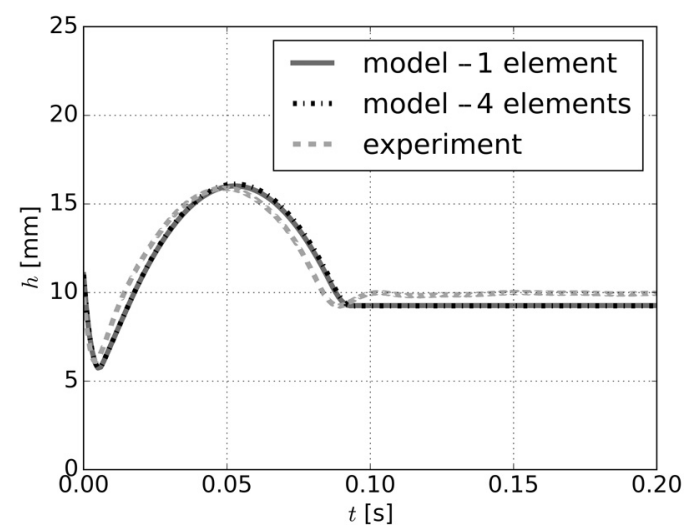

Fig. 11. Comparison of displacement of identified model and impact test for $2 \mathrm{~ms}^{-1}$

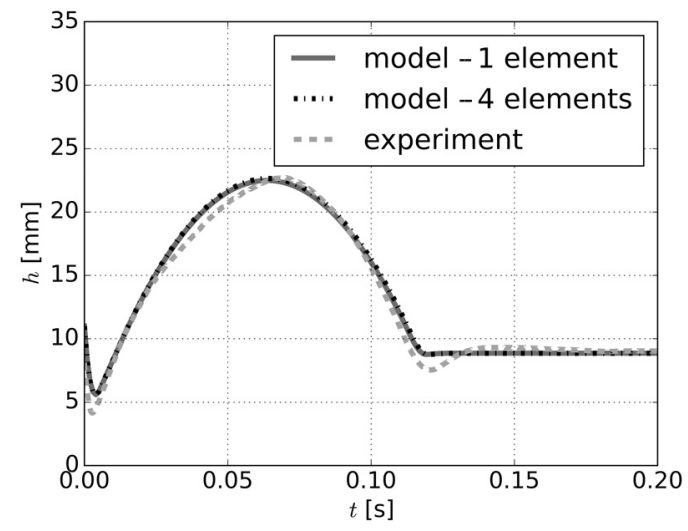

Fig. 13. Comparison of displacement of identified model and impact test for $3 \mathrm{~ms}^{-1}$

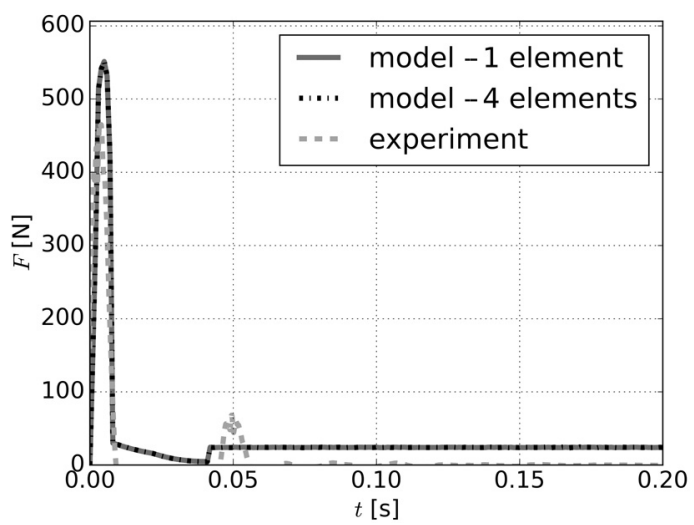

Fig. 10. Comparison of force response of identified model and impact test for $1 \mathrm{~ms}^{-1}$

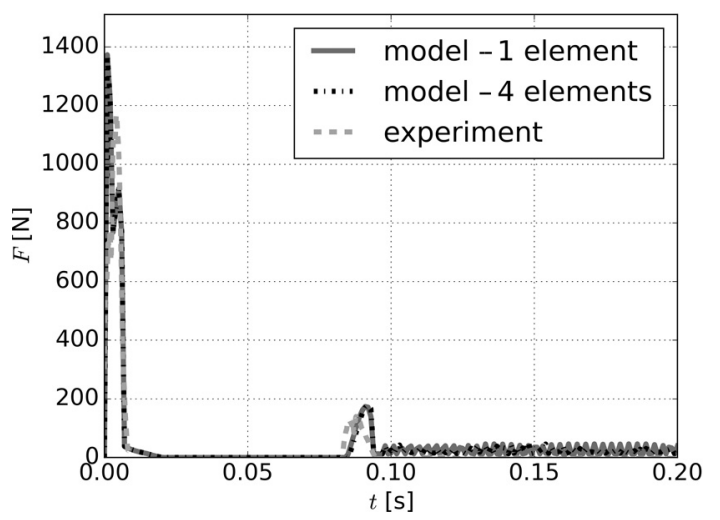

Fig. 12. Comparison of force response of identified model and impact test for $2 \mathrm{~ms}^{-1}$

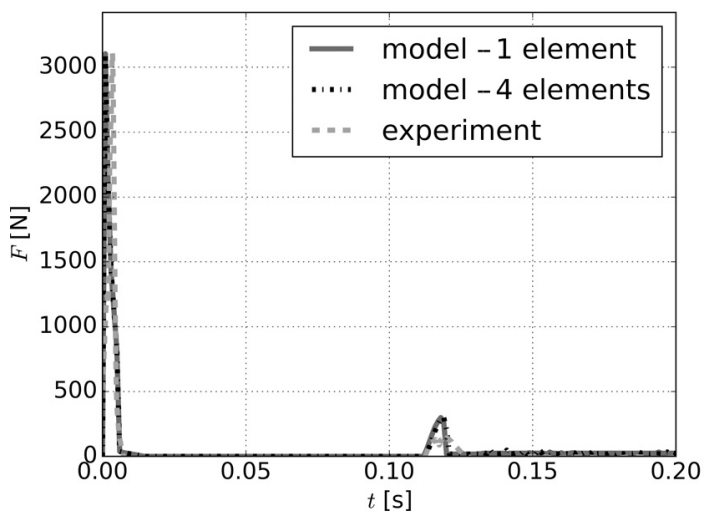

Fig. 14. Comparison of force response of identified model and impact test for $3 \mathrm{~ms}^{-1}$ 
Table 1. Maximal forces comparison for three impact velocities

\begin{tabular}{|l||cccc|}
\hline & Units & $1\left[\mathrm{~ms}^{-1}\right]$ & $2\left[\mathrm{~ms}^{-1}\right]$ & $3\left[\mathrm{~ms}^{-1}\right]$ \\
\hline \hline Experiment & N & 468 & 1168 & 3110 \\
Model - 1 element & N & 551 & 1373 & 3103 \\
Model - 4 elements & N & 551 & 1371 & 3106 \\
\hline Error & $\%$ & 17.7 & 17.5 & 0.2 \\
\hline
\end{tabular}

The best agreement was achieved for the impact velocity $3 \mathrm{~ms}^{-1}$, it was given by the used optimization function (1). For further works, maximal forces were crucial, which are shown in Table 1. The force response of the model was higher than in the experiments in the case of slower impacts, which makes the designs obtained by the model safer. From Table 1 is also apparent that the mesh consisting of 1 element was sufficient for the optimization, the difference between the one element and four elements models is less than $0.5 \%$.

Figs. 15 and 16 show the comparison of the compression and tension tests and their simulations using the identified material model. The force-displacement curves are in very good agreement.

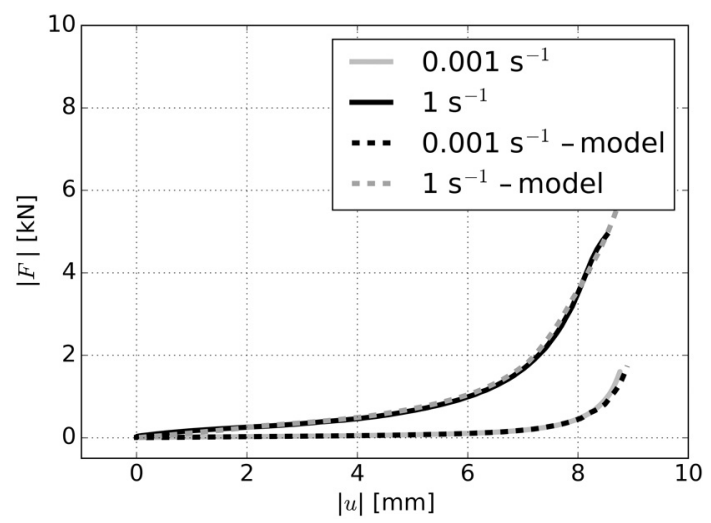

Fig. 15. Comparison of identified model and compression test

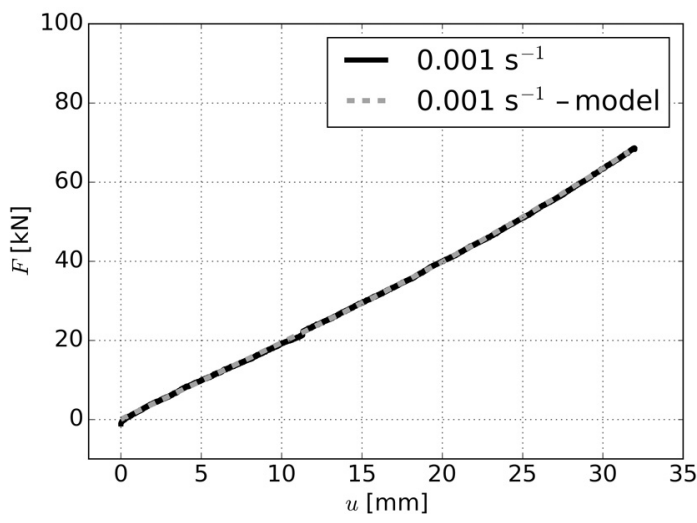

Fig. 16. Comparison of identified model and tension test

\section{Conclusion}

Obtained material model is suitable for strain rates similar to strain rates reached during the standard test ČSN EN 1621-1. The force response of the model was higher than in the experiment in case of the impacts with lower strain rates, which makes the designs obtained by the model safer. The model can be improved by adding more stress-strain curves, which would require other experiments and their models for the identification. Mesh consisting of one element is suitable for optimization, its main advantage is the reduction of computational time. In future work, the influence of temperature on the foam properties will be analysed. It is possible that the ability to absorb energy would be significantly (negatively) affected by higher temperature which is unfortunately common matter in the motorcyclist sport. It will be also necessary to analyse influence of the shape of the foam sample in the future work to show credibility of the final model. Final model will be assigned to the appropriate component of the protector and will be further modified together with material models of its other components to achieve best possible result. 


\section{Acknowledgements}

The work was supported by the research project LTC17001 Exploitation of virtual human model for reducing injury risk of PTW riders as the national link to the COST Action TU1407 Scientific and technical innovations for safer Powered Two Wheelers (PTW) and the internal grant project SGS-2016-059 Computer modelling and monitoring of human body used for medicine. The authors would like to thank the company PSí Hubík for providing foam samples.

\section{References}

[1] Abaqus 6.14 Documentation.

[2] Bonkowski, T., Šoltés, L., Hynčík, L., Kottner, R., Kochová, P., Leather for motorcyclist garments: Multi-test based material model fitting in terms of Ogden parameters, Applied and Computational Mechanics 11 (2) (2017) 129-136. https://doi.org/10.24132/acm.2017.390

[3] Fornells, A., Parera, N., Azpeitia, J. A., Ferris, S., Alba, J. J., Kid-Shell: Safety system protection for childpassengers travelling on powered twowheeled vehicles, Proceedings of the 6th Transport Research Arena, Warsaw, Elsevier, 2016, pp. 3886-3904.

[4] Hynčík, L., Bońkowski, T., Kottner, R., Virtual assessment of motorcycle helmet contribution to decreasing injury risk in impact, Proceedings of the 37th Fisita World Automotive Congress, Chennai, 2018. (in press)

[5] Kottner, R., Kaňáková, S., Šoltés, L., Bońkowski, T., Krytek, J., Mechanical behaviour of foam used in joint protectors, Proceedings of the 56th Conference on Experimental Stress Analysis, Harrachov, Technical University of Liberec, 2018. (in press)

[6] Kottner, R., Mandys, T., Bartošek, J., Kocáb, J., Impact force response of foams and rubbers, Proceedings of the 54th Conference on Experimental Stress Analysis, Srni, University of West Bohemia, 2016, pp. 193-199.

[7] Milne, G., Deck, C., Bourdet, N., Alline, Q., Gallego, A., Carreira, R. P., Willinger, R., Assessment of bicyclist head injury risk under tangential impact conditions, Proceedings of the IRCOBI Conference, Gothenburg, 2013, pp. 735-746.

[8] Škrlec, A., Klemenc, J., Fajdiga, M., Parameter identification for a low-density-foam material model using numerical optimisation procedures, Engineering Computations 31 (7) (2014) 1532-1549. https://doi.org/10.1108/EC-03-2013-0100

[9] Šoltés, L., Bońkowski, T., Kottner, R., Hynčík, L., Drop test of foams used in motorbike protectors, Proceedings of the 55th Conference on Experimental Stress Analysis, Novy Smokovec, Technical University of Kosice, 2017, pp. 27-30. 